\title{
Social Networking Sites Use and Psychological Attachment Need among Indonesian Young Adults Population
}

\author{
Esther Widhi Andangsari, Ihshan Gumilar \& Raymond Godwin \\ Department of Psychology, Bina Nusantara University, Indonesia \\ Correspondence: Esther Widhi Andangsari, Department of Psychology, Bina Nusantara University, Indonesia. \\ E-mail: esther@binus.edu
}

\author{
Received: February 10, 2013 Accepted: February 25, 2013 Available online: June 27, 2013 \\ doi:10.11114/ijsss.v1i2.66 \\ URL: http://dx.doi.org/10.11114/ijsss.v1i2.66
}

\begin{abstract}
The wide-spread use of online social networking sites has sparked many psychological issues and research around the globe. A unique phenomenon has come into existence in which people rely on Facebook to satisfy their attachment need. It is one of the very innately psychological needs that presents throughout a life span. The present study investigated the interaction between attachment style and social networking site use. The result showed that attachment style contributed significantly to the level of social media use. It also pointed out that the attachment style distinguished significantly between active and non-active users. Future research and implications of the study were discussed.
\end{abstract}

Keywords: Attachment, Facebook, Twitter, Young adults, Social media, Indonesian, SNS

\section{Introduction}

Indonesia becomes one of the top five Facebook users in the universe (Grazella, 2013). There are 64 million users of Facebook that come from Indonesia (Grazella, 2013). The country has a wellgrowing market for technological devices. In relation to that, Facebook keeps increasing their service to be more accessible through mobile phone particularly for Indonesian market (Grazella, 2013).In Indonesia, Facebook was used for various purposes from just killing time to giving critics to the government when it raised a fuel price. Mark Zuckerberg's social media product has raised several issues in the society,e.g.,rape cases that begin from chatting in Facebook, posting inappropriate pictures, insulting others through posting harsh words in their walls, and stalking.

There were numerous studies that were conducted to investigate Facebook use, but there was none any study to authors' knowledge that was carried out to look at the interaction between attachment styles and Facebook usage in Indonesian population. Facebook has revolutionized the way traditonal indonesians interact and build a relationship with others. Indonesians who are well-known for keeping traditional values,e.g. face-to-face interaction as a polite form for a first time communication, began to leave the values with the emergence of technology such as Facebook.

Due to that, investigating Facebook and attachment styles in Indonesia is a worthy research that can be a basis to look at how the society changed by adopting technology. Facebook has changed the way people communicate, build a relationship, express emotion, and do self-presentation (Marshall, Bejanyan, Di Castro, \& Lee, 2013; Subrahmanyam, Reich, Waechter, \& Espinoza, 2008). The current study further looked at the interaction between attachment styles of Indonesian and the way of utilizing Facebook as the most growing technological media in the world.

\subsection{Attachment Perspective}

Bowlby (1982) mentioned that early relationship between infants and their caregivers plays a crucial role in shaping a later development. A quality of attachment that was generated by such interaction between infants and caregivers will shape an internal working model that affects one's social expectations and behaviours in the future (Bowlby, 1982).

There are two types of internal working model: secure and insecure. Secure internal working model (secure attachment style) views that others are dependable and can be trusted during difficult times as well as looks at 
positively about oneself. On the other hand, insecure working model (insecure attachment style) refers to a condition in which a sense of basic trust is disturbed that affects the way one puts trust on oneself and others.

Insecure attachment style, which has become a major research theme, is divided into two types: anxiety and avoidant attachment Brennan, Clark, \& Shaver (1998). Anxiety attachment refers to a condition in which people feel negative about themselves, unworthy of love, while maintaining a high desire to attach with others, and expect rejections from others. In other words, they have a negative view about themselves and positive about others. They are preoccupied with a relationship. Avoidant attachment refers to a condition in which people do not want to attach with others because they are afraid that others will neglect them. This condition stems from painful childhood experiences in which people were neglected repeatedly by their caregivers. Consequently, it affects their later development in building relationship with others. They become very hard to trus people whom they think in general neglectful.

Emotional attachment that functions in adult serves the same basic purpose in the early life of children (Hazan \& Shaver, (1987). Should the emotional attachment is not met properly, negative psychological impacts will come out. Hazan and Shaver (1987) further divided attachments for adults into two types: models of self (how one looks at himself), and models of others (how one looks at others).

\subsection{Facebook and Attachment}

People spend more time with Facebook because they want to get close with others (Baker \& Oswald, 2010; Oldmeadow, Quinn, \& Kowert, 2013; Roberts, Smith, \& Pollock, 2000). Even people with attachment issues still have a desire to have an intimacy with others (Oldmeadow et al., 2013). However, people with different attachment styles have different feelings and cognitions about themselves and others that influence the way they interact with them via Facebook. Facebook as a means to communicate with others has been employed uniquely by people with unique types of attachment (Jenkins-Guarnieri, Wright, \& Hudiburgh, 2012; Oldmeadow et al., 2013). It allows people to initiate communication without necessarily showing their non-verbal behaviours such as face expression and gesture. People with insecure attachment have an issue with those non-verbal communication skills that are required in offline situation (Anders \& Tucker, 2000). Thus, online communication such as Facebook and Twitter turn to be a comfortable place to communicate and build relationship.

Facebook has been used by young adults to maintain an intimacy as a developmental task that needs to be dealt with (Subrahmanyam et al., 2008). Anxious attachment people have been found to have a lack of interpersonal communication skills (Anders \& Tucker, 2000; Jenkins-Guarnieri et al., 2012). They are lacking of assertiveness in building communication with others (Anders \& Tucker, 2000). Such inability emerges due to his perception on himself who is unworthy of love. His self-esteem, which may have been affected, hinders him to interact with others in offline condition. People with anxious attachment can have a chance to fulfil their attachment need through Facebook. Spending more time in Facebook and reducing time of face-to-face interaction can supress their feeling of unworthy of love. Then, maintaining a communication with others through Facebook becomes a comfortable place to fulfill their psychological need: attachment and intimacy.

Current study that surveyed more than one hundred couples showed that anxious attachment people are more often to check their couple's Facebook page than avoidant attachment counterpart (Marshall et al., 2013). Such behaviour is mediated by a low level of trust (Marshall et al., 2013). Since the former group has a negative view of themselves, then, it affects the way they put trust on others. They may have a low level of self-esteem, which is reflected on their Facebook usage behaviour. The study further indicated that people with anxious attachment had more jealousy of their partners than avoidant one in terms of using Facebook.

For people with avoidant attachment, they are reluctant to attach themselves with others because they have been neglected very often in their childhood and that experience taught them that others are not dependable(Bowlby, 1982; Griffin, D. \& Bartholomew, 1994). Unlike people with anxious attachment, they tend to avoid using Facebook that provides a chance to build a relationship with others (Anders \& Tucker, 2000). Even though they can access Facebook anytime and anywhere, they choose not to use it because they feel that they can stand on their feet and do not need others to attach with. They showed opposite behaviour of people with anxious attachment in using Facebook (Anders \& Tucker, 2000).

Many studies have been conducted to look at the impacts of Facebook use on human psyche (Raacke \& Bonds-Raacke, 2008; Subrahmanyam et al., 2008). Yet, the above mentioned studies offer a different perspective that the "behaviour" of Facebook is affected by human personality. Facebook, thus, has actually been influenced by how people succesfully build relationships with their caregivers during their childhood period. 


\subsection{Objectives of the Study}

1). To investigate a significant difference between active and non-active users of social networking sites with respect to attachment pattern.

2). To look at a relationship between use of Facebook and Twitter.

Hypothesis

H1: There is a significant difference between a group of active users and of non-active users with respect to attachment pattern styles.

H2: There is a correlation between Facebook and Twitter use.

\section{Method}

\subsection{Participant Characteristics}

The present study recruited healthy participants without any psychological disorders. They should have stayed in Jakarta as an urban area for more than a year, which was assumed to be enough time to make them to be blended into an urban lifestyle, which is inseparable from technology. Additionally, they should have Facebook and Twitter accounts before filling out questionnaires. There were 169 participants: 57(33\%) women and 112(64\%) men.

\subsubsection{Sampling Procedure}

The current sample was recruited with random sampling technique and all of them were undergraduate students of BINUS University, Indonesia, from various faculties. They were approached by research assistants. Should they agree to participate in the study; they were given an informed consent.

\subsection{Measures}

\subsubsection{Relationship Style Questionnaire (RSQ)}

Relationship Style Questionnaire (Griffin, D. \& Bartholomew, 1994) was translated and adapted into Indonesian context. Based on pilot study that was conducted, out of 30 items available in the questionnaire, there were only 17 items that were used in the study due to reliability issues. The scale ranges from 1(Not at all) to 4 (Very much likely). Some of the questions are as follows: "I worry to be hurt if I get too close with others", "I feel very comfortable when I do not emotionally attach with others", and "It is hard for me to trust others".

The questionnaire assessed four types of attachment: Secure, easy to be emotionally close with others and comfortable if there is one is dependent on him, not worry too much about being independent. Fearful, one feels hard to get emotionally close with others and difficult to trust others. Anxiety (preoccupied), one wants to get close with others, but he feels that people find difficult to get close with him. Feeling uncomfortable without close relationship. Avoidant (Dismissing), being comfortable without attachment to others, having close relationship, and prefer to not having others being dependent on him. This type of person feels independent and self-sufficient.

\subsubsection{Social Networking Site Engagement Scale (SNSES)}

The authors constructed SNSES and carried out a pilot study several times to look at its reliability and validity values. The SNSES measured the social networking site use by focusing on participation of using Facebook and Twitter, "I always update my status either in Facebook or Twitter everyday" and "I frequently give comments on other people's status either in Facebook or Twitter", not by the frequency of using Facebook,e.g., "How many times do you log in to your Facebook and Twitter per day". The scale consisted of 12 items $(1=$ Not at all, $4=$ Very much likely). The scale also asked the most used tools to access social networking sites such as Blackberry, iPhone, and Personal computer.

\subsection{Research Design}

The present study employed survey method in which the questionnaires were distributed among BINUS University students and collected after several days. They were asked to complete an informed consent prior to filling out questionnaires and providing personal information. They were free not to provide any answer for any question that they felt too personal. The participation in the study was strictly voluntarily without any effect on their academic matter. The participants filled out the questionnaires within 15-20 minutes. They had a right to withdraw themselves from participation at anytime. After completing the questionnaires, they were thanked and given a small token of appreciation. 


\section{Result}

Table 1. Frequency of active and non-active users of social media sites

\begin{tabular}{lcc}
\hline User Category & $\mathbf{n}$ & \% \\
\hline Non-active & 155 & 91.7 \\
Active & 14 & 8.3
\end{tabular}

The above table showed that the frequency of active and non-active users of social media that were recruited in the present study. There were $155(92 \%)$ non-active users and $14(8 \%)$ of active users.

Table 2. Attachment patterns between a group of active and non-active users

\begin{tabular}{llcccc}
\hline \multicolumn{1}{c}{ Attachment pattern } & Facebook use & M & SD & t & $\boldsymbol{p}$ \\
& & & & & \\
\hline Secure & Non-active & 8.19 & 1.88 & -1.80 & .07 \\
& Active & 9.14 & 1.91 & & \\
& Non-active & 5.29 & 1.58 & 0.33 & .74 \\
& Active & 5.14 & 1.65 & & \\
Fear & & & & \\
Anxiety (Preoccupied) & Non-active & 7.44 & 1.75 & -2.74 & $.01 *$ \\
& Active & 8.78 & 1.76 & & \\
Avoidant (Dismissing) & Non-active & 6.95 & 1.19 & 0.92 & .35 \\
& Active & 6.64 & 1.33 & & \\
\hline
\end{tabular}

$* p<.05$

Table 2 showed that a significant difference between active and non-active users was found in anxiety (preoccupied) attachment style, $t(167)=-2.74, p<.05$. With the rest of attachment patterns, there was no significant difference: Secure, $t(167)=-1.80, \mathrm{p}>0.05$, Fear, $t(167)=.33, p>.05$, Avoidant (Dismissing), $t(167)$ $=.92, p>0.05$. Thus, the first hypothesis was supported in reference to the current data.

With respect to the second hypothesis, the current result revealed that there was a significant correlation between a frequency use (year) of Facebook and of Twitter, $r=.47, p<.001$. Such relationship indicated the more people use Facebook, the more likely they utilize Twitter as part of their social networking site activities.

\section{Discussion}

The first hypothesis was supported by the current available result in which people with anxiety attachment being more active in using Facebook. This is in line with the previous studies that were conducted in the western society (Anders \& Tucker, 2000; Oldmeadow et al., 2013). Since this type of people has a negative view of themselves, which may affect their self-esteem to interact more with others, then Facebook can be a comfortable means to communicate with others (Anders \& Tucker, 2000; Jenkins-Guarnieri et al., 2012; Marshall et al., 2013). The more they spend their time using Facebook, e.g., posting on one's wall or giving comments on someone's post, the more responses that would be received from others. This action can change their perception about themselves gradually that they are actually worthy of love. Consequently, it may increase their level of self-esteem that would make them more able to interact with others. Additionally, the available responses that were gained from others through Facebook are indications that others are available for them in a difficult situation (Hazan \& Shaver, 1987). In other words, they perceive that others who interact or give responses in Facebook would be available for them should they need people to turn to, particularly when they have a problem or just want to share their feelings and thoughts.

In relation to that, nevertheless, there is none study indicated whether the increasing number of relationships that were made in Facebook will actually be put into practice. Future study should look at how much the increasing number of interactions in Facebook would have an impact on offline situation, especially among people with anxiety attachment. Should there is a positive result, Facebook can become a "therapeutic means" for people with anxiety attachment in light of putting their trust on themselves and building relationship with others. Optimistically, it may lead them to the path of secure attachment. 
For people with avoidant attachment, the data did not show a significant difference between active and non-active users in utilizing Facebook. This has supported the previous study that avoidant attachment people were reluctant to use Facebook (Marshall et al., 2013; Oldmeadow et al., 2013). This kind of people tends to avoid using it because they do not trust others to be attached with and do not want to rely on others as well (Hazan \& Shaver, (1987). They feel self-sufficient and independent. Facebook did not facilitate a significant impact on their attachment need. In fact, using Facebook to interact with others may actually remind them with their painful experiences during childhood period in which they were neglected repeatedly by their caregivers. Therefore, Facebook is not a main means for people with avoidant attachment style.

The second hypothesis was supported by the obtained data, a positive correlation between Facebook and Twitter use. It pointed out that the two popular social media are put in one "package". It is very hard to be separated. Combining of using Facebook and Twitter will increase more chance to receive responses from others, from which they can build attachment with others. For instance, should people update their status in Facebook, they can also share it in Twitter. Posting one update in various social media, e.g., Facebook and Twitter, will increase a chance to receive more comments from others, which increase a possibility to have more people to attach with. In addition, people who are not in one's friend circle sometime can also post a comment on someone else's updates; that opens another new chance to create attachment. People may prefer to use Twitter nowadays because it is instant and short, only 140 characters. They can go straight to the point to find current updates while saving time for another task.

In conclusion, online social networking site such as Facebook has turned to serve a basic need of human. Despite negative impacts of Facebook, e.g., internet addiction, stalking, and rape cases that initiated from Facebook, people use it to satisfy their attachment need. Attachment style affects people's online social behavior and expectations, particularly people with anxious attachment. It is because online social networking media allow people to have a close attachment with others without necessarily having anxious feeling as they do in offline relationship.

\subsection{Limitations of the Study}

The present study has several limitations in terms of unbalance number of active and non-active participants. Such condition may have contributed to non-significant difference between active and non-active users with respect to several attachment styles: secure, fear, and dismiss. Also, reducing several items of RSQ may have affected some reliability and validity values to some extent. Since all participants were undergraduate students, the current study cannot be generalized to other populations.

\subsection{Suggestions for Future Studies}

Future research should include more various participants from different background and populations. Considering cultural influences can be taken into account because different places may put different value on the importance of internet and Facebook. Utilizing more rigorous scales in assessing attachment and social networking site behavior can provide a better understanding of how the attachment interacts with online social behavior. Predicting of how much creating communications via Facebook and Twitter can be actualized in offline situation will be a fruitful research in understanding better online behavior.

\section{Acknowledgements}

We would like to thank our research assistants who have collected the data. The research was supported by BINUS University Funding 2012 that was granted to Esther Widhi Andangsari.

\section{References}

Anders, S. L., \& Tucker, J. S. (2000). Adult attachment style, interpersonal communication competence, and $\begin{array}{lllll}\text { social support. } & \text { Personal }\end{array}$ http://dx.doi.org/10.1111/j.1475-6811.2000.tb00023.x

Baker, L. R., \& Oswald, D. L. (2010). Shyness and online social networking services. Journal of Social and Personal Relationships, 27(7), 873-889. http://dx.doi.org/10.1177/0265407510375261

Bowlby, J. (1982). Attachment and loss: Vol. 1. attachment (2nd ed. ed.). New York: Basic Books.

Brennan, K. A., Clark, C. L., \& Shaver, P. R. (1998). Self-report measurement of adult attachment: An integrative overview. In J. A. Simpson \& W.S. Rholes (Eds.), Attachment theory and close relationships (pp. 46-76). New York: Guilford.

Grazella, M. (2013, ). Facebook has 64m active indonesian users. The Jakarta Post. 
Griffin, D. W., \& Bartholomew, K. (1994). The metaphysics of measurement: The case of adult attachment. In K. Bartholomew, \& D. Perlman (Eds.), Advances in personal relationships: Attachment processes in adulthood (pp. 17-52). London: Kingsley.

Griffin, D., \& Bartholomew, K. (1994). Models of the self and other - fundamental dimensions underlying measures of adult attachment. Journal of Personality and Social Psychology, 67(3), 430-445. http://dx.doi.org/10.1037/0022-3514.67.3.430

Hazan, C., \& Shaver, B. (1987). Conceptualizing romantic love as an attachment process. Jounal of Personality and Social Psychology, 52, 511-524.

Jenkins-Guarnieri, M. A., Wright, S. L., \& Hudiburgh, L. M. (2012). The relationships among attachment style, personality traits, interpersonal competency, and facebook use. Journal of Applied Developmental Psychology, 33(6), 294-301. http://dx.doi.org/10.1016/j.appdev.2012.08.001

Marshall, T. C., Bejanyan, K., Di Castro, G., \& Lee, R. A. (2013). Attachment styles as predictors of facebook-related jealousy and surveillance in romantic relationships. Personal Relationships, 20(1), 1-22. http://dx.doi.org/10.1111/j.1475-6811.2011.01393.x

Oldmeadow, J. A., Quinn, S., \& Kowert, R. (2013). Attachment style, social skills, and facebook use amongst adults. Computers in Human Behavior, 29(3), 1142-1149. http://dx.doi.org/10.1016/j.chb.2012.10.006

Raacke, J., \& Bonds-Raacke, J. (2008). MySpace and facebook: Applying the uses and gratifications theory to exploring friend-networking sites. Cyberpsychology \& Behavior, 11(2), 169-174. http://dx.doi.org/10.1089/cpb.2007.0056

Roberts, L. D., Smith, L. M., \& Pollock, C. M. (2000). U r a lot bolder on the net: Shyness and internet use. In R. Crozier W. (Ed.), Shyness: Development, consolidation and change (pp. 121-138)

Subrahmanyam, K., Reich, S. M., Waechter, N., \& Espinoza, G. (2008). Online and offline social networks: Use of social networking sites by emerging adults. Journal of Applied Developmental Psychology, 29(6), 420-433. http://dx.doi.org/10.1016/j.appdev.2008.07.003

\section{$(\mathrm{cc}) \mathrm{Br}$}

This work is licensed under a Creative Commons Attribution 3.0 License. 